\title{
DOI:
}

\section{COMPARATIVE ANALYSIS OF DRAGON AND SNAKE IMAGES IN CHINESE AND RUSSIAN LINGUOCULTURE}

\author{
Gou Yanmin \\ PhD candidate of Department of Foreign Languages \\ of Philological Faculty \\ Peoples' Friendship University of Russia \\ (Moscow, Russia) \\ e-mail: yan04min06@gmail.com
}

\begin{abstract}
The article is devoted to the description of the mythologism "dragon" in the perception of the Chinese people and the zoonym "snake" in Russian linguoculture. The established similarities allowed us to compare these categories in terms of religious and mythological perception, analyze the structure of dictionary entries, and evaluate the paremiological Fund of the Russian and Chinese languages, which includes the components of the snake and dragon, respectively. The research material was the author's card index consisting of 8 Chinese and 9 Russian signs selected from lexicographic sources using a continuous sampling method. The classification of signs and their description in terms of the features of the content plan and structure of construction are given, a comparative analysis of Russian and Chinese signs is carried out to identify linguistic and cultural features. Conclusions are drawn about the historical attitude to the dragon and the snake as similar mythological images in various linguistic cultures.
\end{abstract}

Keywords: mythologism, zoonym, dragon, snake, omens, signs, linguoculturology

\section{СОПОСТАВИТЕЛЬНЫЙ АНАЛИЗ ОБРАЗОВ ДРАКОНА И ЗМЕИ В КИТАЙСКОЙ И РУССКОЙ ЛИНГВОКУЛЬТУРЕ}

\author{
Яньминь Гоу \\ Аспирант кафедры иностранных языков \\ филологического факультета \\ Российский университет дружбы народов \\ (Россия, Москва) \\ e-mail: yan04min06@gmail.com
}

\begin{abstract}
Аннотация. Статья посвящена описанию мифологизма «дракон» в восприятии китайского народа и зоонима «змея» в русской лингвокультуре. Установленные сходства позволили рассмотреть данные номинации в сопоставлении с точки зрения религиозного и мифологического восприятия, проанализировать структуры построения словарных статей, оценить паремиологический фонд русского и китайского языка, включающий компоненты змея и дракон соответственно. Материалом исследования послужила авторская картотека, состоящая из 8 китайских и 9 русских примет, отобранных из лексикографических источников приёмом сплошной выборки. Приведена классификация примет и осуществлено их описание с точки зрения особенностей плана содержания и структуры построения, проведён сопоставительный анализ русских и китайских примет для выявления лингвокультурологических особенностей. Сделаны выводы об исторически сложившемся отношении к дракону и змее как схожим мифологическим образам в различных лингвокультурах.
\end{abstract}

Ключевые слова: мифологизм, зооним, дракон, змея, приметы, лингвокультурология 


\section{ВВЕДЕНИЕ}

По мнению Н.Н. Семененко, «культурно обусловленное содержание вербализованных когнитивных единиц, являющихся оперативными единицами этноязыкового сознания, выражается в национально-культурном компоненте языкового значения» (Semenenko 2011: 165). Такие компоненты, входящие в состав народных примет, позволяют определить специфику языковой картины мира (ЯКМ) той или иной страны и прочитать культурный код её языкового сознания. Вслед за Д.Б. Гудковым под культурным кодом мы понимаем вторичную знаковую систему, использующую «разные материальные и формальные средства для кодирования одного и того же содержания, сводимого в целом к картине мира, к мировоззрению данного социума» (Gudkov 2020: 8-9). Слова, имеющие отношение к культурному коду, могут восприниматься в прямом значении, которое фиксируют лексикографические источники, или ассоциироваться $\mathrm{c}$ мифологическими представлениями, распространёнными в определённом лингвокультурном сообществе. В работе «Философия. Мифология. Культура» А.Ф. Лосев подчёркивает, что «даже всякая неодушевлённая вещь или явление, если их брать как предметы не абстрактно изолированные, но как предметы живого человеческого опыта, обязательно суть мифы» (Losev 1991: 78). Зоонимы, входящие в состав паремий и определяющие индивидуальное мифологическое сознание народа, также можно считать важной составляющей культурного кода, поскольку, изучая паремиологическую картину мира и формируя представление о нём, «каждое новое поколение присваивает культурные ценности и то миропонимание, которое сложилось в данном лингвокультурном пространстве» (Paremiologiya bez granic 2020: 137). Именно поэтому в состав зоонимической лексики входят не только номинации, называющие реально существующих представителей фауны, но и лексемы, фиксирующие названия мифологических (фантастических) существ, активно бытующих как в китайском, так и в русском фольклоре.

\section{ОБЗОР ЛИТЕРАТУРЫ}

Интересом к образу дракона обусловлен ряд лингвокультурологических работ, которые строятся как на сопоставлении восприятия данного фантастического животного у разных народностей (Ю. Чуньбо «Образ дракона в культурах Китая и России» (2012), Г.А. Трофимов «Об антропоморфности змеев и драконов в русском и британском фольклоре» (2015), Ч. Вэньин, Ч. Хайшань, Д.С. Труханова «Образ дракона/змея в русской и китайской культурах» (2017) и др.), так и на описании трансформации его образа в культуре Китая (У.Н. Решетнёва «Образы фантастических существ в китайских пословицах и поговорках» (2006), Б. Цзылун «Историческая эволюция образа дракона в Китае и его характерные черты» (2014), И.В. Казакова «Образ дракона в китайской мифологии, фольклоре и других культурных пластах (2018) и др.).

\section{МЕТОДЫ ИССЛЕДОВАНИЯ}

Выбор методов исследования обусловлен задачами работы и спецификой анализируемого материала: приём сплошной выборки материала из лексикографических источников («Большой словарь китайских пословиц» (гл. ред. Вэнь Дуаньчжэн 2011), Сборник гаданий земледелия (Лян Чжанчжу 1956), «Большой словарь поговорок» (Вэнь Дуаньчжэн 2019), метод лингвокультурологического анализа, описательно-аналитический и сопоставительный методы.

\section{РЕЗУЛЬТАТЫ И ДИСКУССИЯ}

В мифологии Китая центральное место занимают пять священных существ, среди которых дракон является одной из древнейших и основных мифологем и занимает главное место в системе тотемных животных, а в иерархии китайских божеств - «третье после неба и земли» (Sidihmenov 2000: 36). 
Согласно «Словарю современного китайского языка» слово дракон может употребляться в пяти значениях. В рамках данной статьи наиболее значимыми представляются следующие: «龙 (букв. дракон)

名词, 我国古代传说中的神异动物, 身体长, 有麟, 有角, 有脚, 能走, 能飞, 能游泳, 能兴云降 雨。(букв. Существительное, загадочное животное в древних китайских легендах. Оно имеет длинное тело, чешую, рога и ноги. Оно может ходить, летать, плавать, может поднимать облака дождя. Дракон может вызывать облака и дожди);

2) 封建时期用龙作为帝王的象征, 也用来指帝王使用的东西。(букв. Во время феодальной династии дракон использовался как символ императора, а также использовался для обозначения вещей, используемых императором)» (ССКЯ 2005: 840).

Первое значение лексемы дракон характеризует внешний вид животного и описывает физические функции, однако культурологические источники содержат более полное его описание, представляя дракона синкретичным существом: «тело змеи, брюхо лягушки, рога оленя, глаза зайца, уши коровы, золотую чешую карпа, волосатый хвост и лапы тигра с четырьмя или пятью орлиными когтями» (Malyavin 2000: 339). Из второго значения, приведенного в словарной статье, становится понятно, что образ дракона в китайской культуре имеет высокий статус и связывается в представлениях народа с императорскими династиями, считаясь самым известным символом «могущества и власти» (Malyavin 2000: 339).

В 1986 году при раскопках поселения Чахай в провинции Ляонин были найдены змееподобные орнаменты на керамике, относящиеся к неолитической культуре Синлунва и датируемые VI тысячелетием до н.э. Китайские исследователи предположили, что на одной из керамик изображен загнутый хвост дракона, а на второй - фрагмент его спиралевидного туловища. Эта находка, которая теперь считается самыми ранними из изображений дракона, даёт возможность утверждать, «что культ дракона существовал еще в эпоху неолита» (Stupnikova 2015: 22).

В. Я. Сидихменов в китайской мифологической традиции выделяет четыре типа дракона: «небесный дракон, охранявший обители богов; божественный дракон, посылавший ветер и дождь; дракон земли, определявший направление и глубину рек и ручьев; дракон, охранявший сокровища» (Sidihmenov 2000: 36 - 37). Кроме того, сунский император Хуэйцзун (徽宗, 1082-1135) канонизировал драконов-царей пяти цветов, что позволило впоследствии классифицировать этих фантастических существ согласно цветовой гамме в соответствии со схемой пяти первоэлементов усин (五行). Выделяют лазуритового дракона (Цинлун (青龍)), олицетворяющего восток и считающегося самым сострадательным из всех; Алого дракона (Чжулун (朱龍)), символизирующего юг и дарующего благословение озерам; Жёлтого дракона (Хуанлун (黃龍)), благожелательно выслушивающего все прошения и ассоциирующегося с центром Вселенной; добродетельного и невинного Белого дракона (Байлун (白龍)), покровительствующего западу и Черного, или сокровенного дракона (Сюаньлун (玄龍)), живущего в глубинах мистических вод и охраняющего север.

Значимость образа дракона в китайской культуре подчеркивает и большой паремиологический фонд, включающий такие пословицы и поговорки, как 龙生九种, 九种各别 (букв. У дракона родились девять сыновей, и все друг от друга отличаются) - 'не все дети в одной семье одинаковы, не все умны и талантливы, не все выполняют наставления родителей') (БСПк 2019: 894), 龙生龙, 虎生虎 (букв. У дракона рождаются драконы, а у тигра рождаются тигры) - 'каковы родители, таковы и дети’ (БСПк 2019: 895), 鱼龙混杂 (букв. Перемешались рыбы и драконы) - так говорят, когда смешалось и хорошее, и плохое, когда где-то есть вместе добрые и подлые люди (БФС 2004: 1562), 鲤鱼跳龙门 (букв. Карп перепрыгнул ворота дракона) - так говорят о человеке, который совершил стремительную карьеру, преодолел в своей жизни важное препятствие, добился большого 
успеха (БСПк 2019: 894), 龙无云不行, 鱼无水不生 (букв. Дракон без облаков не летает, рыба без воды не живет) - о том, что даже для развития большого таланта нужны соответствующие условия (БСПк 2019: 896), 龙眼识珠, 凤眼识宝, 牛眼识青草 (букв. Глаза дракона видят жемчуг, глаза феникса - сокровище, глаза буйвола - рисовую солому) - выдающиеся личности имеют большие возможности и большие достижения, а посредственность остается посредственностью (БСПк 2019: 896) и др. Приведённые паремии, «являясь репрезентантами национальной картины мира, помогают осознать национальную специфику и дополнить данные о языковой картине мира» (Lomakina 2010: 217). Использование компонента дракон подчёркивает значимость данного образа в восприятии китайцев и формирует положительное представление о человеке.

С целью выявления китайских паремий с номинацией дракон было изучено 3 источника («Большой словарь китайских пословиц» (гл. ред. Вэнь Дуаньчжэн 2011), Сборник гаданий земледелия (Лян Чжанчжу 1956), «Большой словарь поговорок» (Вэнь Дуаньчжэн 2019)) и отобрано 8 примет, которые можно классифицировать следующим образом: 1. Приметы, характеризующие изменения в погоде в зависимости от поведения животного: 云从龙, 风从虎。(БСКПц 2011: 1304) (букв. Где дракон, там и тучи; где тигр, там и ураган); 多龙多旱。(БСКПц 2011: 176) (букв. Где драконов много, там будет засуха); 龙下频, 主旱。(CHzhanchzhu 1956: 103) (букв. Драконы собираются - к засухе); 龙多乃旱。(CHzhanchzhu 1956: 103) (букв. Драконов много - к засухе); 白龙瞟娘, 必主雷雨。(БСКПц 2011: 7) (букв. 13-го мая по лунному календарю белый дракон возвращается домой к матери, в тот день бывает гроза с ливнем), 凡见黑龙主无雨, 纵有亦不多。白龙下, 雨必到。(CHzhanchzhu 1956: 103) (букв. Где чёрный дракон, там дождя не будет; где белый дракон, скоро будет дождь);

2. Приметы, которые содержат компоненты, указывающие на взаимосвязь дракона с сельским хозяйством: 二月二, 龙抬头; 小仓满, 大仓流。(БСКПц 2011: 196) (букв. Второго числа второго месяца по лунному календарю дракон поднимает голову; все амбары полны);

3. Приметы, отражающие взаимосвязь природных явлений с появлением драконов: 龙行带雨, 虎行带风。民间认为, 云雾翻涌, 将有龙出现; 风声大作, 将有虎出没。(БСПк 2019: 896) (букв. Люди верят: если бурно сгрудятся облака и туман, то появятся драконы; если ветер бурно поднимется, будут тигры);

4. Приметы, содержащие колоративы: 白龙瞟娘, 必主雷雨。(БСКПц 2011: 7) (букв. 13-го мая по лунному календарю белый дракон возвращается домой к матери, в тот день бывает гроза с ливнем), 凡见黑龙主无雨, 纵有亦不多。白龙下, 雨必到。(CHzhanchzhu 1956: 103) (букв. Где черный дракон, там дождя не будет; где белый дракон, скоро будет дождь).

Следует отметить, что 6 из 8 китайских примет, включающих номинацию дракон, носят фенологический характер. Объяснение этому находится в лингвокультурологических источниках. Согласно бытующим в народе мифам и легендам, царём драконов считается Лунван - божество вод, дождя и колодцев, которому суеверные люди молились, боясь наступления засухи. По поверьям Лунван появлялся второго февраля, благодаря чему количество осадков на севере Китая увеличивалось. Способность драконов вызывать дождь ассоциируется в народном представлении с влиянием этих фантастических существ на благополучие в сельскохозяйственной отрасли, что подчёркивает прогноз, содержащийся в конечной части приметы 二月二, 龙抬头; 小仓满, 大仓流。(БСКПц 2011: 196) (букв. Второго числа второго месяца по лунному календарю дракон поднимает голову; все амбары полны).

Образ дракона в паремиологической картине мира взаимодействует с облаками, поскольку дракон - мифологическое существо, способное летать. Такая закономерность прослеживается в примете 龙行带雨, 虎行带风。民间认为, 云雾翻涌, 将有龙出现; 风声大作, 将有虎出没。(БСПк 2019: 896) (букв. Люди верят, что если бурно сгрудятся облака и туман, то появятся драконы; если 
ветер бурно поднимется, будут тигры). Кроме того, соотнесённость возможностей дракона с облаками видна и в пословице 龙无云而不行。(БСПк 2019: 896) (букв. Дракон не может вызывать дождь без облаков).

В китайских паремиях находит отражение и разделение драконов по цветовому соответствию. Так, указание на животных черного и белого цвета содержится в фенологических приметах 白龙瞟娘, 必主雷雨。(БСКПц 2011: 7) (букв. 13-го мая по лунному календарю белый дракон возвращается домой к матери, в тот день бывает гроза с ливнем), 凡见黑龙主无雨, 纵有亦不多。白龙下, 雨必到。(CHzhanchzhu 1956: 103) (букв. Где черный дракон, там дождя не будет; где белый дракон, скоро будет дождь). Употребление точной даты в первой примете имеет чёткие обоснования: 13 мая в Китае считается днём рождения Байлуна. Согласно существующим поверьям, в этот день он обязательно возвращается к матери, что китайцы ассоциируют с появлением на небе белых облаков, которые и считаются предвестниками ливня с грозой. Вторая примета позволяет сопоставить появления Чёрного и Белого драконов. Считаясь покровителем глубинных вод, Сюаньлун сдерживает осадки, а Байлун, наоборот, предвещает дождь.

В русской культуре образ дракона встречается преимущественно в фольклоре. В народных сказках это фантастическое животное всегда выступает в качестве отрицательного персонажа. В словарных статьях различных русских лексикографических источников, содержащих трактовку лексемы дракон, выделяется общая сема 'змея' или 'ящерица', дающая возможность соотносить дракона с данным подотрядом пресмыкающихся. Так, в Малом академическом словаре под редакцией А.П. Евгеньевой приводится следующее определение: “Дракон, -а, м. 1. Сказочное чудовище в виде крылатого огнедышащего змея, пожирающее людей и животных. 2. Древесная ящерица некоторых тропических стран, обладающая способностью к полету” (МАС Т.1). Кроме того, синонимом слова дракон в «Словаре живого великорусского языка» В.И. Даля выступают номинации диавол, чёрт (ТСЖВЯ Т.1: 489). Подобные определения объясняют негативное отношение к дракону в русском культурологическом пространстве.

Формированию подобного восприятия могли способствовать несколько причин. Во-первых, змей - первое животное, появившееся в текстах Ветхого Завета и способствующее грехопадению людей: «Змей был хитрее всех зверей полевых, которых создал Господь Бог. И сказал змей жене: подлинно ли сказал Бог: не ешьте ни от какого дерева в раю? И сказала жена змею: плоды с дерев мы можем есть, только плодов дерева, которое среди рая, сказал Бог, не ешьте их и не прикасайтесь к ним, чтобы вам не умереть. И сказал змей жене: нет, не умрете, но знает Бог, что в день, в который вы вкусите их, откроются глаза ваши, и вы будете, как боги, знающие добро и зло» (Bibliya Gl.3).

Во-вторых, в славянской мифологии змей относится к «низшим» животным и обитает у корней «мирового дерева (мирового древа) - символа мироздания, мировой «оси» и центра Вселенной» (Koval' 2016:61), соотносимых в народном сознании с преисподней, поэтому олицетворяет грех.

Такое восприятие змея находит отражение в русской фольклорной и литературной традиции славян. В поздних мифах змей становится огнедышащим и крылатым, т.е. приобретает черты дракона, воплощающего силу подземного потустороннего мира и являющегося людям в облике огненной кометы в вихре. Так, крылатый змей-искуситель в образе муромского князя Павла летал к главной героине «Повести о Петре и Февронии Муромских», написанной в середине XVI века, а богатыри русских народных сказок неистово борются со Змеем Горынычем, безжалостно разоряющим земли, крадущим детей и уничтожающим мирные поселения («Три подземных царства», «Победитель змея», «Бой на Калиновом мосту» и др.).

Образ змея является популярным персонажем фольклорной традиции славян и ему уделяется значительное внимание в сказках, легендах, поверьях и паремиологическом пространстве, при этом обнаруживаются сходства в основополагающих внешних характеристиках с образом дракона в китайской культурной традиции («в китайских народных речениях самыми значимыми частями тела 
в облике дракона выделяются голова и хвост. Обычно их сопоставляют со змеиными» (Reshetnyova 2006)), поэтому считаем возможным вслед за А.П. Терентьевым-Катанским рассмотреть приметы с зоонимом змея в сопоставлении с номинацией дракон.

В ходе исследования из «Словаря русских суеверий» и «Пословиц русского народа» было отобрано 9 русских примет (7 и 2 соответственно), содержащих компонент змея, которые можно классифицировать по следующим основаниям:

1. Приметы, отражающие необычные способности змеи: Коли убитого ужа (или: змею) повесить на осине, то очнется и ужалит своего убийцу (Dal' 2: 378), Высушенная голова первой увиденной весной и убитой гадюки, если ее повесить на шею, излечивает любую лихорадку (Grushko: $103)$;

2. Приметы, указывающие на негативные последствия взаимодействия со змеёй: Кожа змеи, сброшенная во время линьки и украдкой подложенная под подушку какому-нибудь человеку, может стать причиною его смерти (Grushko: 174), Змея на деревне - к болезням (Grushko: 174);

3. Приметы, отражающие суеверные представления народа: Если весною, убив змею, разрезать ей брюхо, положить туда три горошины и зарыть в землю, то потом вырастет ивет (Grushko: 110); Убить гадюку - доброе дело, за которое сорок грехов снимается с человека (Grushko: 103), Кто змею убьет, тому прошается сорок грехов (Grushko: 174);

4. Приметы, характеризующие изменения в погоде в зависимости от поведения животного: Если убить змею и повесить на березу, пойдет дождь (Dal' 2: 370), (Grushko: 174).

Стереотипы этноязыкового сознания находят отражение в приметах первой и второй группы. Данные паремии обладают схожестью внутренней формы: во второй части содержится не рекомендация, а констатация следствия, данного в первой части: очнется и ужалит своего убийцу, излечивает любую лихорадку, может стать причиною его смерти, к болезням. При этом языковая кодировка культурной действительности (термин Н.Н. Семененко) примет рассматриваемых групп различна. В прогнозирующей части примет, отражающих необычные способности змеи, речь идет об убитых животных. Причем в паремии Коли убитого ужа (или: змею) повесить на осине, то очнется и ужалит своего убийцу (Dal' 2: 378) отражается не только вера славян в способность убитой змеи оживать, но и подчеркивается значение в этом процессе дендросимвола - осины. По мнению Т.А. Агапкиной, «исследование растительной символики составляет заметный фрагмент современного научного дискурса (фольклористического, этнографического, этнолингвистического), связанного с изучением традиционной славянской культуры» (Agapkina 2012: 29). Осина в русских народных представлениях считается проклятым деревом и отмечается «у восточных и западных славян связью с демонами» наряду с бузиной и вербой (Agapkina 2012: 35). Из осины был сделан крест, на котором распяли Христа, а также гвозди и спицы, используемые для мучений, по одному из поверий считается, что дрожанием своих ветвей это дерево выдало прятавшихся под ним Богородицу с Христом во время бегства в Египет. Кроме того, христианское неприятие дерева обусловлено тем, что на осине повесился Иуда. В связи с этим «бузина и осина не использовались практически ни в каких сферах семейной обрядности и магии, а также считались малопригодными в бытовом отношении, зато играли заметную роль в народной медицине (на них символически “переносили” болезни) и в колдовской магии» (Agapkina 2012: 35). Указания на то, что, по убеждениям русского и белорусского народа, убитая змея могла оживать именно от осины содержатся и в этнолингвистическом словаре «Славянские древности» (Gura 1995: 335).

В славянской традиции известно «применение змеи (её головы, хвоста, сердца, крови, жира, яда и особенно слинявшей кожи) в народной медицине: для лечения опухолей (полес., укр.), укусов (з.-укр., болг.), лихорадки (полес., болг., хорв.), запоев (укр. волын) и т.д.» (Gura 1995: 338), что констатирует прогноз приметы Высушенная голова первой увиденной весной и убитой гадюки, если ее повесить на шею, излечивает любую лихорадку (Grushko: 103). 
На соотнесённость змеи и смерти либо недуга в русских народных представлениях указывают лингвокогнитивные категории паремий второй группы. Внутренняя форма и смысловая структура приметы Кожа змеи, сброшенная во время линьки и украдкой подложенная под подушку какомунибудь человеку, может стать причиною его смерти (Grushko: 174) свидетельствуют о вере славян в чёрную магию и возможность прибегнуть к ней, желая досадить своему врагу.

Третья группа представлена тремя паремиями, отражающими связь образа змеи с суеверными представлениями славян. Так как змея считалась в христианской религиозной традиции порождением дьявола, то при встрече её необходимо было убить, чтобы простились грехи. Данное убеждение находит смысловое отражение в конечной части двух примет: Убить гадюку - доброе дело, за которое сорок грехов снимается с человека (Grushko: 103), Кто змею убьет, тому прошается сорок грехов (Grushko: 174). При этом план выражения паремий в прогнозе различен. В первой примете убийство гадюки (змеи) содержит открытую оценку деяния через адъектив доброе, т.е. 'основанный на расположении к людям, желании добра; хороший, нужный, полезный людям’ (МАС Т.1). Стоит отметить, что в примете, взятой из «Словаря русских суеверий», уточняется разновидность змеи гадюка (“Ядовитая змея, широко распространенная в Европе, Азии, Африке” (МАС Т.1)). О ядовитых змеях и связанных с ними поверьях упоминает В.А. Мошков в очерке «Гагаузы Бендерского уезда» и отмечает следующее: «Змея (йылан). Кто убьет змею, тому прощается один грех, потому что в змее непременно находится шайтан. Если кто убьет это животное, то труп его нельзя бросать где попало, а нужно зарыть в землю для того, чтобы мухи не перенесли яду на какого-нибудь человека» (Moshkov 1901: 63). Шайтан, согласно словарю, ‘в мусульманской мифологии злой дух, дьявол' (МАС Т.4), значит, олицетворение змеи с дьяволом можно считать традицией, свойственной многим народам мира, тем более что награда за совершённое деяние тоже схожа - прощение грехов. В анализируемых приметах для обозначения действий, связанных с избавлением от грехов, используются глаголы синонимичного ряда прощается и снимается.

Причины такого отношения к змеям обосновал А.С. Ермолов еще в начале XX века: «Змей народ очень боится, может быть, даже более, чем следует, так как часто не различает змей совершенно безвредных, вроде ужей и медяниц, от змей действительно ядовитых: гадюк, ехидны и т. п.» (Ermolov 1905: 386). При этом объяснить смысл конечной части приметы Если весною, убив змею, разрезать ей брюхо, положить туда три горошины и зарыть в землю, то потом вырастет цьет (Grushko: 110) представляется достаточно сложным. Возможно, выросший цветок, можно воспринимать как награду за убийство гада, содействие в порождении прекрасного, доброго. На сложность однозначного прочтения большинства примет, в отличие от пословиц, загадок и поговорок, обращает внимание Н.Н. Семененко и называет объективную причину этого: «Своеобразным аналогом парадокса у примет выступает немотивированная (или слабо, символически мотивированная) логическая связь между исходным событием и итоговым прогнозом» (Semenenko 2011: 206).

Ещё одним дендросимволом славянской мифологии является берёза - «дерево “счастливое”, оберегающее от зла, и одновременно вредоносное, связанное с нечистой силой и душами умерших» (Vinogradova, Usachyova 1995: 156). Слово берёза является структурным компонентом фенологической приметы Если убить змею и повесить на берёзу, пойдет дождь, выявленную как в «Пословицах русского народа» В.И. Даля, так и в «Словаре русских суеверий» Е.А. Грушко, Ю.М. Медведева. Однако установить культурологическую взаимосвязь между структурными единицами рассматриваемой паремии не удалось. Это может быть объяснено тем, что предсказываемое событие касается явлений природы и не «участвует в сложной цепи моделирования человеческой деятельности в соответствии с обусловливающими факторами» (Kul'kova 2012: 29), а сама примета, относясь к группе дескриптивных паремий, выполняет репрезентативную функцию.

\section{ЗАКЛЮЧЕНИЕ}


Таким образом, несмотря на различное восприятие образа дракона в двух лингвокультурах, стало возможным определить генетическую связь между драконом, вымышленным мифологическим персонажем, и змеёй, реально существующим животным, т.к. «речь идет о пресмыкающемся, близком к змее и живущем в воде» (Terent'ev-Katanskij 2004: 26), и провести сопоставительный анализ китайских и русских примет, включающих данные компоненты. При наличии внешнего сходства среда обитания этих животных различна: в народной афористике Китая дракону подвластна водная и воздушная стихия, а в России змея считается покровителем подземного потустороннего мира. В китайских приметах данный факт находит подтверждение в вызываемых ассоциациях дракона с облаками и землёй. В русских паремиях указаний на среду обитания змеи отмечено не было, однако упоминаемые в русских приметах дендросимволы (осина и береза), говорят о связи змеи с земным существованием.

В связи с разным восприятием анализируемых существ в лингвокультурах двух стран типология китайских и русских примет различна. В китайской ЯКМ преобладают фенологические приметы (6 из 8), тогда как в русском языковом пространстве была выявлена только одна подобная паремия. В китайской классификации примет находит отражение соотнесенность мифологического деления драконов согласно цветовой гамме в соответствии со схемой пяти первоэлементов у-син, а также взаимосвязь природных явлений и сельскохозяйственных процессов с поведением драконов. Классификация русских примет основывается на славянских суеверных представлениях, связанных с образом змеи.

Отмечается схожесть китайских и русских примет в их структурном решении: в прогнозе паремиологических единиц обеих лингвокультур в основном содержится констатация факта, а не рекомендации. В связи с этим китайские паремии с номинацией дракон и русские паремии с номинацией змея подтверждают идею, высказанную Н.Н. Семененко: «...приметы, несмотря на свой прямолинейно-рекомендательный характер практически не касаются категории морали» (Semenenko 2011: 206), а из-за определенной парадоксальности мышления, отмечаемой исследователями в этих паремиологических единицах, трактовать причинно-следственные закономерности оказывается невозможным.

\section{REFERENCES}

Agapkina, T.A. (2012) Derev'ya v tradicionnoj kul'ture slavyan: problema sistemnogo opisaniya [Trees in the traditional culture of the Slavs: the problem of system description]// Etnograficheskoe obozrenie, № 6, 29 -43 .

Bibliya. Knigi Svyashchennogo pisaniya Vethogo i Novogo Zaveta. Ka-nonicheskie [Bible. Books of Scripture of the Old and New Testaments. Ka-nonic] (1990) - Hel'sinki : St. Michel Print Mikkeli, 1224 s.

Vinogradova, L.N., Usachyova, V.V. (1995) Beryoza [Birch tree]// Slavyanskie drevnosti: Etnolingvisticheskij slovar' v 5-ti tomah / Pod obshchej red. N.I. Tolstogo. - T.1:A (Avgust) - G (Gus') Institut slavyanovedeniya RAN. Moscow: Mezhdunarodnye otnosheniya, 156-159.

Grushko, E. A. (1995) Slovar' russkih sueverij, zaklinanij, primet i poverij [Dictionary of Russian superstitions, spells, signs and beliefs]/ E. A. Grushko, YU. M. Medvedev - Nizhnij Novgorod: Russkij kupec i Brat'ya slavyane, $560 \mathrm{~s}$. - CPC.

Gudkov, D.B. (2020) Lyudi i zveri. Russkie precedentnye imena i zoonimy v nacional'nom mife:

Lingvokul'turologicheskij slovar'. [People and beasts. Russian precedent names and zoonyms in the national myth: Linguocultural Dictionary] Moscow: - M.: LENAND, $200 \mathrm{s.}$

Gura, A.V. (1999) Zmeya [Snake]// Slavyanskie drevnosti: Etnolingvisticheskij slovar' v 5-ti tomah / Pod obshchej red. N.I. Tolstogo. - T.2: D (Davat') - K (Kroshki). Institut slavyanovedeniya RAN. Moscow: Mezhdunarodnye otnosheniya, 333-338. 
Dal', V. I. (1996) Poslovicy russkogo naroda: Sbornik: v 2 t. [Proverbs of the Russian people: Collection: in 2 volumes]. T.2 - M.: TERRA; «Knizhnaya lavka - RTR», T. 1-2. - ПPH.

Dal', V.I. (1999) Tolkovyy slovar' zhivogo velikorusskogo yazyka [Explanatory dictionary of the living Great Russian language] Moscow: Russkij yazyk. - ТСЖВЯ.

Ermolov, A. S. (1905) Narodnaya sel'skohozyajstvennaya mudrost' [Folk agricultural wisdom]. SPb, $620 \mathrm{s.}$

Koval', V. I. (2016) Mifologicheskie verovaniya vostochnyh slavyan : Posobie po kursu «Slavyanskaya mifologiya» [Mythological Beliefs of the Eastern Slavs: A Manual on the Course "Slavic Mythology"] Gomel': GGU im. F. Skoriny, 270 s.

Kul'kova, M.A. (2012) Russkie i nemeckie paremii: kognitivno-diskursivnyj podhod k izucheniyu: Uchebnoe posobie [Russian and German Paremias: A Cognitive-Discursive Approach to Learning: A Study Guide]- Kazan': «Pechat'-Servis-XXI vek», 214 s.

Lomakina, O.V. (2010) Paremii v tekstah L.N. Tolstogo: lingvokul'turologicheskij kommentarij [Paremias in the texts of L.N. Tolstoy: a linguocultural commentary]// Vestnik Orlovskogo gos. Unta, 6 (14), 217-221.

Losev, A.F. (1991) Filosofiya. Mifologiya. Kul'tura [Philosophy. Mythology. Culture], Moscow: Politizdat, $525 \mathrm{~s}$.

Malyavin, V.V. (2000) Kitajskaya civilizaciya [Chinese civilization]. Moscow: "Izdatel'stvo Astrel'", 632 s.

Moshkov, V. A. (1901) Gagauzy Benderskogo uezda. VIII. Verovaniya [Gagauz, Bendery district. VIII. Beliefs] // Etnograficheskoe obozrenie. № 4, 1-80.

Paremiologiya bez granic: monografiya [Paremiology without borders: monograph] (2020)// pod red. M.A. Bredisa, O.V. Lomakinoj. Moscow: RUDN, $244 \mathrm{~s}$.

Reshetnyova, U.N. (2006) Obrazy fantasticheskih sushchestv v kitajskih poslovicah i pogovorkah// Elektronnyj nauchnyj zhurnal «Vestnik Omskogo gosudarstvennogo pedagogicheskogo universiteta», vypusk 2006.

Semenenko, N.N. (2011) Russkie paremii: funkcii, semantika, pragmatika: Monografiya [Russian paremias: functions, semantics, pragmatics: Monograph]. Staryj Oskol: Izd-vo ROSA, 335 s.

Sidihmenov, V. YA. (2000) Kitaj: stranicy proshlogo [China: pages of the past]. Smolensk: Rusich, 464 s.

Slovar' russkogo yazyka: V 4-h t. [Dictionary of the Russian language: In 4 volumes.] (1981-1984)/ Pod red.

A. P. Evgen'evoj. Moscow: Russkij yazyk. - MAC

Stupnikova, V.V. (2015) K voprosu o proiskhozhdenii kitajskogo drakona [On the question of the origin of the Chinese dragon] //Vestnik Vyatskogo gosudarstvennogo gumanitarnogo universiteta, №8, s.21-26.

Terent'ev-Katanskij, A.P. (2004) Illyustracii k kitajskomu bestiariyu. Mifologicheskie zhivotnye drevnego Kitaya [Illustrations for the Chinese bestiary. Mythological animals of ancient China]. SPb: FormaT, $224 \mathrm{~s}$.

梁章钜. 农候杂占. 北京: 中华书局, 1956. 116页 (Lyan CHzhanchzhu (1956) Sbornik gadanij zemledeliya [A collection of farming fortune-telling]. Pekin: Kitajskoe knizhnoe izdatel'stvo, 116 s.)

俗语大辞典：温端政主编.北京：商务印书馆, 2019. 2522页(Bol'shoj slovar' pogovorok [Large

dictionary of sayings] (2019)/ Ven' Duan'chzhen, gl. red. Pekin: Kommercheskoe Izdatel'stvo, 2522 s.) -

БСПк.

中国浐语大辞典: 辞海版/温端政主编.上海辞书出版社, 2011. 1137页(Bol'shoj slovar' kitajskih poslovic

[Comprehensive Dictionary of Chinese Proverbs] (2011): Enciklopedicheskoe izdanie (Cyhaj)/ Ven' Duan'chzhen, gl. red. SHanhaj: SHanhajskoe izdatel'stvo leksikograficheskoj literatury, 1398 s.) - БСКПц. 现代汉语词典.中国社会科学院语言研究所词典编辑室编（第5版）, 北京: 商务印书馆, 2005.

1866页 (Slovar' sovremennogo kitajskogo yazyka [Modern Chinese Dictionary] (2005)/ pod red. slovarnogo redakcionnogo otdela Instituta lingvistiki Kitajskoj akademii obshchestvennyh nauk. 5-e izd. Pekin: Kommercheskoe Izdatel'stvo, 1866 s.) - ССКЯ. 


\section{For citation:}

Gou, Ya. (2020). Comparative analysis of dragon and snake images in Chinese and Russian linguoculture // International Scientific-Pedagogical Organization of Philologists "WEST-EAST " (ISPOP). Scientific Journal WEST-EAST. Vol 3 N1 (October, 2020). pp. - 38. doi:

\section{Для цитирования:}

Гоу, Ян. (2020). Вопросы преподавания предмета лингвострановедения (с целью комплексного обучения грузинскому языку и культуре) // International Scientific-Pedagogical Organization of Philologists “WEST-EAST” (ISPOP). Scientific Journal WEST-EAST. Vol 3 N1 (October, 2020). C. 11 16. doi:

Information about the author: Gou Yanmin - $\mathrm{PhD}$ candidate of Department of Foreign Languages of Philological Faculty, Peoples' Friendship University of Russia, Moscow, Russia; e-mail: yan04min06@gmail.com

Сведения об авторе: Гоу Яньминь - аспирант кафедры иностранных языков филологического факультета Российского университета дружбы народов, г. Москва, Россия; e-mail: yan04min06@gmail.com

Manuscript received: 15/08/2020

Accepted for publication: $15 / 09 / 2020$

Рукопись получена: 15/08/2020

Принята к печати: 15/09/2020 